\title{
Prevalence and predictors of wound infection in elective clean and clean/contaminated surgery in Khartoum Teaching Hospital, Sudan
}

\author{
Abubaker Ibrahim Elbur' ${ }^{1}$, Yousif MA ${ }^{1}$, Ahmed Sayed Ahmed ElSayed ${ }^{2}$, Manar Elsheikh Abdel-Rahman ${ }^{3}$ \\ 1. Department of Clinical Pharmacy, College of Pharmacy, Taif University, \\ Al-Haweiah,Taif, Kingdom of Saudi Arabia. \\ 2. Department of Cardiothoracic Surgery, Alshaab Teaching Hospital, Khartoum, Sudan \\ 3. Faculty of Mathematical Sciences, University of Khartoum, Khartoum, Sudan
}

doi: 10.3396/ijic.v8i4.036.12

\begin{abstract}
Surgical site infections are the second most common cause of hospital acquired infections. The objectives of this study were to quantify the rate of wound infection and to identify risk factors associated for its prevalence among patients admitted for elective surgery in Khartoum Teaching Hospital in Sudan. A prospective study was conducted. All patients, aged >18 years admitted during March 1st 2010 to 31th October 2010 were recruited. Baseline data was collected before the patient was operated. Patients were followed up to one month for detection of wound infection using bedside and post-discharge surveillance. A total of 1387 patients were included with a mean age of $35 \pm 14$ years and $1138(82 \%)$ were females. More than three quarters were healthy $(79.3 \%)$ and 1367 (98.6\%) patients were operated on conventionally. The total number of the performed surgical procedures was 1426 . The rate of wound infection was found to be $9 \%$. The majority of the infected wounds 120 (96\%) were superficial and only $5(4 \%)$ were deep incisional. Univariate analysis revealed that five variables were significantly associated with the prevalence of wound infection; namely patient's body mass index ( $\mathrm{P}=0.041)$, comorbidity ( $\mathrm{P}=0.006)$, presence of diabetes $(\mathrm{P}=0.010)$, ASA score $(\mathrm{P}<0.0001)$ and laparoscopic surgical technique $(\mathrm{P}=0.007)$. Multivariate logistic analysis showed that ASA score 2 and ASA score $>3$, [adjusted OR 1.9 (1.2-3.0), $\mathrm{P}=0.006$ and adjusted OR 3.6 (2.0-6.7); $\mathrm{P}<0.001$ respectively], laparoscopic surgical technique [adjusted OR 5.5 (2-14.8); $\mathrm{P}=0.001]$ were mostly significantly associated with the prevalence of wound infection. The rate of wound infection was high with patient's physical status being strong predictor of infection.
\end{abstract}

\section{Key words}

Surgical wound infection+epidemiology+prevention and control; risk factors; Sudan; Surgical procedures, elective

\section{Corresponding Author}

Abubaker Ibrahim Elbur

Department of Clinical Pharmacy, College of Pharmacy, Taif University,

P.O. Box: 888, 21974, Al-Haweiah, Taif, Kingdom of Saudi Arabia.

Email: bakarelbu@yahoo.co.uk 


\section{Introduction}

Surgical site infection (SSI) is increasingly recognized as a measure of the quality of patient care by both healthcare providers and the public. ${ }^{1}$ SSIs are the second most common cause of hospital acquired infections. ${ }^{2}$ Incisional infections are controlled easily; however deeper and more extensive infections may have devastating consequences. ${ }^{3}$ The occurrence of such infections increases the length of hospital stay, admission to the intensive care unit, incidence of readmission and risk of mortality. ${ }^{4}$

Many factors influence the rate of infection; these factors can be categorized into those that arise from patient's health status, those related to the physical environment where surgical care is provided and those resulting from clinical interventions that increase the patient inherent risk. ${ }^{5}$

The most commonly identified patient-related factors are pre-existing diabetes and/or preoperative hyperglycemia, obesity or malnutrition, pre-existing remote body site infection, recent tobacco use, contaminated or dirty wound, colonization with microorganisms, and preoperative hypothermia. ${ }^{6}$

The identification of the risk factors allows elucidation of those that are modifiable from those that are not and helps in the development of interventional strategies to reduce the risk of infection.?

The main objectives of this study were to quantify the rate of wound infection and to identify the risk factors associated for its prevalence among patients admitted for elective clean and clean- contaminated procedures.

\section{Hospital}

The study was conducted in Khartoum Teaching Hospital in Sudan which was established in 1904. The hospital is currently a thousand bed tertiary referral hospital. It covers all the major specialities including medicine, surgery, obstetrics and gynaecology, urology, psychiatry, paediatric surgery and orthopaedics.

\section{Methods}

\section{Study design}

A prospective study was conducted; whereby all adult patients whose ages were $\geq 18$ years old admitted for elective clean and clean-contaminated surgical procedures were recruited prospectively. Emergent surgical procedures were excluded due to the limited financial and human resources available for the conduction of the research. The procedures were distributed among three departments: General Surgery, Obstetrics and Gynaecology and Urology. Patient was excluded in the presence of one or more of the following criteria: use of antibiotic/s for non prophylactic purposes on the same day of surgery or the patient had antibiotic/s and stopped it 48 hours before surgery, principal diagnosis suggestive of a preoperative infectious disease, procedure involving the insertion of an implant, surgical procedure that did not involve incision, patient already recruited in the study and again scheduled for surgery during the study period, patient refused to participate in the study, patients that did not complete the follow up period, and patient died before completion of one month period after surgery.

\section{Sample size}

A total of 1387 patients were included during the period $1^{\text {st }}$ March to $31^{\text {st }}$ October 2010.

\section{Data collection}

Data was collected in real time by trained nurses using a pre-coded questionnaire. The data was obtained either directly from the patient, or by observations or from the patient's file. The following data were recorded: gender, age/year, dates of admission, surgery and discharge, body mass index and presence of comorbidities. The American Society of Anesthesiologists score (ASA score) $)^{8}$ was recorded as $(1=$ healthy, $2=$ mild systemic disease, $3=$ severe systemic disease, $4=$ life threatening disease and $5=$ moribund), surgical discipline, grade of operator (surgeon, registrars, medical officer \& house officers), surgical technique (classic versus laparoscopic technique), wound class (clean versus clean-contaminated), name of operation, category of operation, duration of operation in hours, and the use of surgical drain were also documented. A section in the questionnaire was designed to collect data on wound infection (occurrence, when detected during admission or after discharge and clinical signs).

Wound infection was detected by two methods: Bedside and post-discharge surveillance. Bedside 
surveillance involved following the patient during hospital admission and started from the day after surgery until the patient was discharged from the hospital. Post-discharge surveillance was conducted by phoning the patients for up to 3 telephone calls during a period of one month after discharge. A trained nurse asked each patient structured questions about the presence of any sign/s of wound infection. Wound infection definition and diagnosis was based on the criteria of the Center of Disease Control (CDC) ${ }^{9}$ except for the duration of surgery that was defined as $<1$ hour and $\geq 1$ hour.

\section{Outcomes \& Potential Predictors}

Presence of wound infection was considered as the main study outcome. Potential predictors included were patient's age in years, patient's body mass index, presence of other disease/s, diabetes, ASA score, surgical discipline, grade of operator, type of surgical technique, wound classification, duration of operation in hours, surgical drain and pre and post operative stay in days.

\section{Statistical Analysis}

Percentages and means were used to describe the variables. Analysis aimed to develop a multivariate model to allow prediction of outcome in the presence of potential predictors or covariates. Crude logistic regression analyses were performed as initial steps of qualifying covariates to be included in multivariate logistic regression analyses. Covariates with $p$-values $<=0.25$ were included to develop an initial reduced model. ${ }^{10}$ Multicolinearity among the covariates was assessed using variance inflation factors. Variables that tested insignificant (with $p$-values $>0.05$ ) were then eliminated from this model and interactions were tested. Each variable was sequentially removed at a time and its significance was tested. Likelihood ratio tests were used to compare models and Hosmer and Lemeshow test was used to assess goodness of fit of the final model. ${ }^{10}$ All statistical tests were conducted by using STATA version $12 .{ }^{11}$

Table I. Patients and procedures characteristics

Background characteristics

\section{Gender}

Male

Female

Age (years)

$<30$

30 to $<40$

40 to $<50$

$>=50$

Body mass index $\left(\mathrm{Kg} / \mathrm{m}^{2}\right)$ (n)

1138

20 to $<25$

\section{Co-morbidity}

Yes

\section{Diabetes}




\begin{tabular}{|c|c|c|}
\hline \multicolumn{3}{|l|}{ ASA score } \\
\hline 1 & 1100 & 79.3 \\
\hline 2 & 208 & 15.0 \\
\hline $3+$ & 79 & 5.7 \\
\hline \multicolumn{3}{|l|}{ Surgical discipline } \\
\hline Obstetrics and Gynecoloy & 725 & 52.3 \\
\hline General surgery & 540 & 38.9 \\
\hline Urology & 122 & 8.8 \\
\hline \multicolumn{3}{|l|}{ Operator } \\
\hline Surgeon & 563 & 40.6 \\
\hline $\begin{array}{l}\text { Others (registrars, medical officer \& house } \\
\text { officers) }\end{array}$ & 804 & 58.0 \\
\hline Missing & 20 & 1.4 \\
\hline \multicolumn{3}{|l|}{ Skin preparation } \\
\hline Isopropyl alcohol + chlorohexidine & 1173 & 84.6 \\
\hline Isopropyl alcohol + detergent & 129 & 9.3 \\
\hline Isopropyl alcohol + lodine & 73 & 5.3 \\
\hline Missing & 12 & 0.8 \\
\hline \multicolumn{3}{|l|}{ Preoperative antibiotic } \\
\hline Yes & 1359 & 98 \\
\hline No & 28 & 2 \\
\hline
\end{tabular}

\section{Surgical technique}

Classic

Laparoscopic

\section{Wound classification}

Clean

Clean contaminated

961

\section{Duration of operation/ hour}

$<1$

$>=1$

Missing

\section{Surgical drain}

Yes

405

980

841

60.6

541

5

39.0

0.4

No

Missing

Pre operative time

0-1 day

1085

2

$>1$ day

302

\section{Post operative time}

0-1 day

139

516

29.2

2 days

360

3 days

372

1387
70.7

0.1

78.2

21.8

10.0

37.2

26.0

26.8
Total 


\section{Results}

\section{Patients' characteristics}

Overall 3656 patients were operated on; of them $1769(48.4 \%)$ were recruited according to the defined criteria. The patients completed the follow up period were 1387 (78.4\%) with a mean age of $35 \pm 14$ years. The patients lost for follow up were $368(20.8 \%)$ and $14(0.8 \%)$ died.

Females accounted for $82 \%$ of the patients that completed the follow up period. Healthy subjects $(79.3 \%)$ were the majority and obese patients were $19.2 \%$. Table I shows the distribution of patients by background characteristics.

\section{Surgical procedures}

A total of $725(52.3 \%)$ patients had their procedures done in the Obstetrics and Gynaecology Department, $540(38.9 \%)$ and $122(8.8 \%)$ in General Surgery and Urology Departments respectively amounting to a total of 1426 performed procedures. The classic surgical technique was used in $98.6 \%$ of the studied procedures. More than two third of the operations were classified as clean -contaminated. Duration of operation for nearly $60 \%$ of the patients was $<1$ hour. Table I shows the characteristics of the performed surgical procedures and Table II presents the distribution of the performed surgical procedures.

\section{Hospital stay}

The median duration of hospital stay was 4 days (mean $4 \pm 0.08$ days). The median preoperative hospital stay was one day (mean $1.8 \pm 2.7$ days); while the median postoperative stay was 3 days (mean $3.6 \pm 3.5$ days).

\section{Rate of wound infection}

Out of the total patients included in this study, the wound healed satisfactory for $1262(91.0 \%)$ patients and $125(9 \%)$ had a wound infection. The signs of wound infections were detected during hospital

Table II. The distribution of the performed clean and clean- contaminated surgical procedures

\begin{tabular}{|c|c|c|c|}
\hline Clean procedure & $\begin{array}{r}\text { Frequency } \\
(\%) \\
\end{array}$ & Clean contaminated procedure & $\begin{array}{r}\text { Frequency } \\
(\%) \\
\end{array}$ \\
\hline Neck surgery & $157(11.0 \%)$ & Cesarean section & $578(40.5 \%)$ \\
\hline Mastectomy & $97(6.8 \%)$ & Open cholecystectomy & $98(6.9 \%)$ \\
\hline Hernia repair & $75(5.3 \%)$ & Abdominal hysterectomy & $65(4.5 \%)$ \\
\hline Varicocelectomy & $19(1.3 \%)$ & Myomectomy & $47(3.3 \%)$ \\
\hline Orchidectomy & $17(1.2 \%)$ & Laprotomy & $46(3.2 \%)$ \\
\hline Hydrocelectomy & $16(1.1 \%)$ & Prostatectomy & $32(2.2 \%)$ \\
\hline Thoracic surgery & $9(0.6 \%)$ & Laparoscopic cholecystectomy & $20(1.4 \%)$ \\
\hline Vascular surgery & $8(0.6 \%)$ & Tubes ligation & $18(1.2 \%)$ \\
\hline Orchidopexy & $5(0.4 \%)$ & Vesicolithotomy & $14(1.0 \%)$ \\
\hline \multirow[t]{11}{*}{ Others } & $24(1.7 \%)$ & Nephrectomy & $14(1.0 \%)$ \\
\hline & & Ovariancystectomy & $13(0.9 \%)$ \\
\hline & & Appendectomy & $10(0.7 \%)$ \\
\hline & & Pyelolithotomy & $8(0.6 \%)$ \\
\hline & & Gastric surgery & $8(0.6 \%)$ \\
\hline & & Splenectomy & $7(0.5 \%)$ \\
\hline & & Ureterolithotomy & $7(0.5 \%)$ \\
\hline & & Colon surgery & $5(0.4 \%)$ \\
\hline & & Small bowel surgery & $4(0.3 \%)$ \\
\hline & & Oesophageal surgery & $3(0.2 \%)$ \\
\hline & & Others & $3(0.2 \%)$ \\
\hline Total & $427(30 \%)$ & Total & $1000(70 \%)$ \\
\hline
\end{tabular}


stay for $15(12 \%)$ patients. Wound infection was recognized during the post-discharge period for 110 (88\%) patients; for $63(57.3 \%)$ their infections were confirmed by the surgical units that performed the procedures when they returned back to the hospital and $47(42.7 \%)$ reported the signs through telephone contacts. The majority of the infected wounds 120 $(96 \%)$ were superficial and only $5(4 \%)$ were classified as deep incisional.

The rate of wound infection was $18.8 \%, 17.8 \%$ and $13.4 \%$ among patients operated on for the removal of the prostate gland, gallbladder, and benign or malignant breast tumours respectively. Table III shows the rate of wound infection by category of surgical procedure.

\section{Wound infection risk factors}

Univariate logistic analysis revealed that five variables were significantly associated with the prevalence of wound infection; namely patient's body mass index $(P=0.041)$, co-morbidity $(P=0.006)$, presence of diabetes $(P=0.010)$, ASA score $(P=0.000)$ and laparoscopic technique $(P=0.007)$ (Table IV). Multivariate logistic analysis showed that ASA score and laparoscopic technique were the only significant predictors of wound infection after controlling for all other potential confounders (Table IV). Patients with ASA score 2 had almost twice the odds of developing wound infection compared with patients who had ASA score 1 [adjusted OR 1.9 (1.2-3.0), $P=0.006$ ]. This odds almost doubled for patients with $\mathrm{ASA} \geq 3$ [adjusted $\mathrm{OR}$ 3.6 (2.0-6.7); $P<0.001]$. Patients who had operations using laparoscopic technique had almost 6 fold odds of developing wound infection compared to those who had operations using the classic technique [adjusted OR 5.5 (2-14.8); $P=0.001]$.

\section{Discussion}

Despite improvements in prevention, SSIs remain a significant clinical problem as they are associated with substantial mortality and morbidly and impose severe demand on healthcare resources. ${ }^{12}$ More than $3 \%$ of the surgical patients may probably be affected by surgical site infections. ${ }^{4}$

Table III. Percentages of patients with wound infection by category of surgical procedure

\begin{tabular}{lrrrr} 
Category of surgical procedure & $\begin{array}{r}\text { No of infected } \\
\text { patients }\end{array}$ & Percentage & Total & Confidence interval \\
\hline Oesophageal surgery & 1 & 33.3 & 3 & - \\
Prostatectomy & 6 & 18.8 & 32 & $(0.07-0.36)$ \\
Hydrocelectomy & 3 & 18.8 & 16 & - \\
Cholecystectomy & 21 & 17.8 & 118 & $(0.11-0.26)$ \\
Vesicolithotomy & 2 & 14.3 & 14 & - \\
Mastectomy & 13 & 13.4 & 97 & $(0.07-0.22)$ \\
Gastric surgery & 1 & 12.5 & 8 & - \\
Vascular surgery & 1 & 12.5 & 8 & - \\
Pyelolithotomy & 1 & 12.5 & 8 & - \\
Cesarean section & 48 & 8.3 & 578 & $(0.06-0.11)$ \\
Hernia repair & 6 & 8.0 & 75 & $(0.03-0.17)$ \\
Abdominal hysterectomy & 6 & 9.2 & 65 & $(0.03-0.19)$ \\
Nephrectomy & 1 & 7.1 & 14 & \\
Laprotomy & 3 & 6.5 & 46 & $(0.01-0.18)$ \\
Neck surgery & 7 & 4.5 & 157 & $(0.02-0.09)$ \\
Myomectomy & 1 & 2.1 & 47 & - \\
Others & 4 & 14.8 & 27 & - \\
\hline Total & $\mathbf{1 2 5}$ & & &
\end{tabular}


Table IV. Risk factors for wound infection

\begin{tabular}{|c|c|c|c|c|c|c|}
\hline \multirow[b]{2}{*}{ Covariates } & \multirow{2}{*}{$\begin{array}{l}\% \text { with } \\
\text { wound } \\
\text { infection }\end{array}$} & \multirow[b]{2}{*}{$\mathbf{n}$} & \multicolumn{2}{|c|}{ Univariable analysis } & \multicolumn{2}{|c|}{ Multivariable analysis } \\
\hline & & & $\begin{array}{r}\text { Crude OR }(95 \% \\
\mathrm{CI})\end{array}$ & p-value & $\begin{array}{r}\text { Adjusted } \\
\text { OR }(95 \% \mathrm{CI})\end{array}$ & p-value \\
\hline Gender & & & & 0.914 & & \\
\hline Male & 8.8 & 249 & 1.0 & & & \\
\hline Female & 9.1 & 1138 & $1.0(0.6-1.7)$ & & & \\
\hline Age (years) & & & & 0.129 & & \\
\hline$<30$ & 8.0 & 412 & 1.0 & & & \\
\hline 30 to $<40$ & 8.4 & 510 & $1.1(0.7-1.7)$ & & & \\
\hline 40 to $<50$ & 7.5 & 201 & $0.9(0.5-1.7)$ & & & \\
\hline$>=50$ & 12.9 & 264 & $1.7(1.0-2.8)$ & & & \\
\hline Body mass index $(\mathrm{kg} / \mathrm{m} 2)$ & & & & 0.041 & & \\
\hline$<20$ & 9.7 & 134 & 1.0 & & 1.0 & \\
\hline 20 to $<25$ & 7.4 & 570 & $0.7(0.4-1.4)$ & & $0.8(0.4-1.6)$ & 0.575 \\
\hline 25 to $<30$ & 8.2 & 417 & $0.8(0.4-1.6)$ & & $0.9(0.5-1.9)$ & 0.861 \\
\hline$>=30$ & 13.5 & 266 & $1.5(0.7-2.9)$ & & $1.8(0.9-3.6)$ & 0.109 \\
\hline Co-morbidity & & & & 0.006 & & \\
\hline Yes & 15.0 & 173 & 1.0 & & & \\
\hline No & 8.2 & 1214 & $0.5(0.3-0.8)$ & & & \\
\hline Diabetes & & & & 0.010 & & \\
\hline Yes & 19.4 & 62 & 1.0 & & & \\
\hline No & 8.5 & 1325 & $0.4(0.2-0.8)$ & & & \\
\hline ASA score & & & & $<0.001$ & & \\
\hline 1 & 7.4 & 1100 & 1.0 & & 1.0 & \\
\hline 2 & 13.5 & 208 & $2.0(1.2-3.1)$ & & $1.9(1.2-3.0)$ & 0.006 \\
\hline $3+$ & 20.0 & 79 & $3.2(1.8-5.8)$ & & $3.6(2.0-6.7)$ & $<0.001$ \\
\hline Surgical discipline & & & & 0.142 & & \\
\hline Obstetrics and Gynecoloy & 7.7 & 725 & 1.0 & & & \\
\hline General surgery & 10.9 & 540 & $1.5(1.0-2.2)$ & & & \\
\hline Urology & 8.2 & 122 & $1.1(0.5-2.2)$ & & & \\
\hline Operator & & & & 0.369 & & \\
\hline Surgeon & 8.2 & 563 & 1.0 & & & \\
\hline $\begin{array}{l}\text { Others( registrars, medical } \\
\text { officer \& house officers) }\end{array}$ & 9.6 & 804 & $1.2(0.8-1.7)$ & & & \\
\hline Missing & & 20 & & & & \\
\hline Surgical technique & & & & 0.007 & & \\
\hline Classic & 8.7 & 1367 & 1.0 & & 1.0 & \\
\hline Laparoscopic & 30.0 & 20 & $4.5(1.7-11.9)$ & & $5.5(2.0-14.8)$ & 0.001 \\
\hline Wound Classification & & & & 0.387 & & \\
\hline Clean & 8.0 & 426 & 1.0 & & & \\
\hline Clean contaminated & 9.5 & 961 & $1.2(0.8-1.8)$ & & & \\
\hline Duration of operation/hour & & & & 0.333 & & \\
\hline$<1$ & 8.4 & 841 & 1.0 & & & \\
\hline$>=1$ & 10.0 & 541 & $1.2(0.8-1.7)$ & & & \\
\hline Missing & & 5 & & & & \\
\hline
\end{tabular}




\begin{tabular}{|c|c|c|c|c|}
\hline Surgical drain done & & & & 0.481 \\
\hline Yes & 9.9 & 405 & 1.0 & \\
\hline No & 8.7 & 980 & $0.9(0.6-1.3)$ & \\
\hline Missing & & 2 & & \\
\hline Pre- operative time & & & & 0.532 \\
\hline $0-1$ day & 8.8 & 1085 & 1.0 & \\
\hline$>1$ day & 9.9 & 302 & $1.1(0.7-1.8)$ & \\
\hline Post- operative time & & & & 0.117 \\
\hline 0-1 day & 5.0 & 139 & 1.0 & \\
\hline 2 days & 7.9 & 516 & $1.6(0.7-3.7)$ & \\
\hline 3 days & 10.8 & 360 & $2.3(1.0-5.3)$ & \\
\hline 4+ days & 10.2 & 372 & $2.1(0.9-4.9)$ & \\
\hline Total & & 1387 & & \\
\hline
\end{tabular}

The analysis of the demographic variables of the patients included in this study revealed that; the number of females operated on was the majority. This may be partially explained by the fact that the number of patients recruited from the Obstetrics and Gynecology Department were more than those recruited from the other two departments. Brown et al..$^{13}$ in their study also found a high percentage of females (61\%). Out of the total number of patients included in this research; 19\% were $\geq 50$ years old. In many countries; populations are becoming older; and increasing number of elderly patients are being referred for surgery. The occurrence of chronic diseases among those patients decreases their immunity and contributes to the increased risk of SSI; postoperative morbidity, and mortality. ${ }^{14}$ The results revealed that $19.2 \%$ of the patients operated on were obese. Several studies of diverse populations of patients showed that the risk of postoperative infection among obese patients is clearly higher, in particular, their risk of SSI. ${ }^{15}$

The study determined that the overall rate of wound infection was $9 \%$. This is in agreement with the rate observed by Lilani et al. ${ }^{16}$ as they reported a rate of $8.95 \%$ in such type of surgical interventions. However, the rate of infection in the clean wounds was high $(8.0 \%)$ in this study when compared to the rate of $(3.03 \%)$ reported in the above mentioned study. ${ }^{16}$ Postoperative infections after clean procedures are most probably caused by bacteria that are part of the skin flora. Exogenous sources may also be a factor, such as infected or colonized healthcare workers, the operating room environment or instruments. ${ }^{17}$ The increased rate of infection among patients operated on for clean operations may be attributed to improper adherence to infection control measures for disinfection of the skin of both the patient and healthcare workers, and sterilization of surgical instruments.

The rate of wound infection after clean-contaminated operations was $9.5 \%$. It was low when compared with the rate of infection of $17.8 \%$ and $19.4 \%$ that was respectively reported by Eriksen et al. ${ }^{18}$ and Mosood et al. ${ }^{19}$ In such type of clean- contaminated surgeries the expected range was between $4-10 \%{ }^{6}$

Wound infection rate among patients operated on for the removal of the prostate gland was $18.8 \%$; Brown et al. ${ }^{20}$ found, in their multivariate analysis, that prostate surgery was the strongest predictor of infection. The observed rate of postoperative wound infection after cholecystectomy procedures was $17.8 \%$. Soleto et al. ${ }^{21}$ in their study observed a rate of $15 \%$ among patients operated on for removal of the gallbladder. Surprisingly the rate of wound infection among patients operated on for laparoscopic removal of the gallbladder was $30 \%$. The increased rate among those patients may be attributed to the failure in the sterilization process of the laparoscope. Also as this surgical technique was not commonly used in this hospital; the improper tissue handling during the procedure may be a contributory factor in increasing the risk of infection. In contrast to our finding Petrosillo et al. ${ }^{22}$ observed no significant difference in SSI rate between patients operated on for removal of the gallbladder by both techniques. 
The analysis of risk factors showed that infection rate increased in older patients with ages $\geq 50$ years when compared with other patients' subgroups, but this results not statistically significant; Neumayer et al. ${ }^{23}$ found an association between the prevalence of SSI and patient's age $>40$ years old. Univariate analysis of risk factors in this study showed that; the rate of wound infection increased in diabetics and obese patients with body mass index $\geq 30 \mathrm{~kg} / \mathrm{m}^{2}$. Di Leo et al. ${ }^{24}$ found by multivariable analysis both the above mentioned factors were independently associated with a higher risk of surgical site infection. Multivariable logistic regression analysis showed that the patient physical status as measured by ASA score was significantly associated with the incidence of wound infection. Likewise Narong et al. ${ }^{25}$ identified among other factors poor physical status according to ASA classification to be associated with SSI.

The increased rate of infection observed in this study at the departmental level or per surgical category may be attributed to the high number of surgical interventions performed each day which may affect appropriate patient assessment and preoperative preparation. This was beside the limited resources dedicated for the implementation of proper infection control measures.

Despite the fact that there was an infection control committee in the hospital during the study time, it was observed that there was no system in place to collect data about hospital acquired infections. This may contribute to the increased rate of infection in this study. Surveillance of hospital-acquired infections with feedback to the clinical staff has been shown in previous studies to be associated with reduced rates of wound infections. ${ }^{26-28}$

The majority of wound infections in the current study occurred during the post-discharge period. This may be explained by the fact that the median postoperative stay after the studied procedures was very short (median was 3 days). This result emphasized the importance of post-discharge surveillance in identifying the actual infection rates.

Some patients may fail to identify minor signs of wound infection when interviewed through telephone contact and this can be one of the limitations of this study. Also there was not another method available to follow up the patient when communication with them was lost.

The authors recommend strict adherence to infection control measures, giving infection prevention more attention with allocation of resources, and stressing the importance of the establishment of a network for regular surveillance of nosocomial infections. Strict adherence to the standardized steps involved in the sterilization process of the laparoscope is mandatory.

\section{Acknowledgements}

The authors highly appreciate the co-operation of the staff members of Khartoum Teaching Hospital who participated at different stages of the study.

\section{Funding}

Part of this work was financially supported by Amipharma Laboratories, Pharma Exir Company and Tabouk Medical Company in Sudan.

\section{References}

1. Humphreys $\mathrm{H}$. Preventing surgical site infection. Where now? J Hosp Infect 2009; 73: 316-322. http://dx.doi.org/10.1016/j. jhin.2009.03.028

2. Wong ES. Surgical site infection. In: Mayhall CG, editor. Hospital Epidemiology and Infection Control. Philadelphia: Lippincott Williams \& Wilkins; 2004. p. 287-310.

3. Cheadle WG. Risk factors for surgical site infection. Surg Infect 2006; 7(supp 1): S7-S11. http://dx.doi.org/10.1089/ sur.2006.7.s1-7

4. Kirkland KB, Briggs JP, Trivette SL, Wilkinson WE, Sexton DJ. The impact of surgical site infections in 1990s: attributable mortality, excess length of hospitalization and extra-costs. Infect Control Hosp Epidemiol 1999; 20: 225-230. http:// dx.doi.org/10.1086/501572

5. Barie PS. Surgical site infections: epidemiology and prevention. Surg Infect 2002; 3(Suppl 3): S9-S21. http:// dx.doi.org/10.1089/sur.2002.3.s1-9

6. Barnard B. Prevention of surgical site infections. Infection Control Today 2003; 7: 57-60.

7. Bruke JP. Infection control- a problem for patient safety. $N$ Engl / Med 2003; 348: 651-6. http://dx.doi.org/10.1056/ NEJMhpr020557

8. American Society of Anesthesiologists. New classification of physical status. Anesthesiology 1963; 24: 111.

9. Horan TC, Gaynes RP, Martone WJ, Jarvis WR, Emori TG. CDC definitions of nosocomial surgical site infections, 1992: a modification of CDC definitions of surgical wound infections. Infect Control Hosp Epidemiol 1992; 13: 606-609. http://dx.doi.org/10.1086/646436

10. Hosmer DW, Lemeshow S. Applied Logistic Regression. 2. New York, USA: John Wiley and Sons; 2000. http://dx.doi. org/10.1002/0471722146

11. StataCorp 2011, Stata Statistical Software: Release 12. College Station, TX: StataCorp LP.

12. Owens CD, Stoessel K. Surgical site infections: epidemiology, microbiology and prevention. J Hosp Infect 2008; 70(Supp 2): 3-10. http://dx.doi.org/10.1016/S0195-6701(08)60017-1 
13. Brown SM, Eremin SR, Shlyapnikov SA, et al. Prospective surveillance for surgical site infection in St. Petersburg, Russian Federation. Infect Control Hosp Epidemiol 2007; 28: 319-325. http://dx.doi.org/10.1086/509849

14. Kaye KS, Sloane R, Sexton DJ, Schmader KA. Risk factors for surgical site infections in older people. I Am Geriatr Soc 2006; 54: 391-396. http://dx.doi.org/10.1111/j.15325415.2005.00651.x

15. Anaya AD, Dellinger EP. The obese surgical patient: A susceptible host for infection. Surg Infect 2006; 7: 473-480. http://dx.doi.org/10.1089/sur.2006.7.473

16. Lilani SP, Jangale N, Chowdhary A, Daver GB. Surgical site infection in clean and clean -contaminated cases. Indian J Med Microbiol 2005; 23: 249-252.

17. Prtak LE, Ridgway EJ. Prophylactic antibiotics in Surgery. Surgery 2009; 27: 431-434.

18. Eriksen HM, Chugulu S, Kondo S, Lingaas E. Surgical site infections at Kilimanjaro Christian medical center. I Hosp Infect 2003; 55: 14-20. http://dx.doi.org/10.1016/S01956701(03)00225-1

19. Masood A, Shams NA, Obaidullaa K, Manzar S. Postoperative wound infection: A surgeon dilemma. Pakistan Journal of Surgery 2007; 23: 41-47.

20. Brown S, Kurtsikashvili G, Alonso-Echanove J, et al. Prevalence and predictors of surgical site infection in Tbilisi; Republic of Georgia. J Hosp Infect 2007; 66: 160-166. http:// dx.doi.org/10.1016/j.jhin.2007.03.007

21. Soleto L, Pirard M, Boelaert M, et al. Incidence of surgical site infections and the validity of the National Noscomial Infection Surveillance System Risk Index in a general surgical ward in Santa Cruz; Bolivia. Infect Control Hosp Epidemiol 2003; 24: 26-30. http://dx.doi.org/10.1086/502111
22. Petrosillo N, Drapeau CM, Nicastri E, et al. Surgical site infections in Italian hospitals: a prospective multicenter study. BMC Infectious Diseases 2008; 8: 34, http://www.citeulike. org/article/2486233. [Accessed May 17, 2012]. http://dx.doi. org/10.1186/1471-2334-8-34

23. Neumayer L, Hosokawa $\mathrm{P}$, Itani $\mathrm{K}$, El-Tamer M, Henderson WG, Khuri SF. Multivariable predicators of postoperative surgical site infection after general and vascular surgery: results from the patient safety in surgery study. I Am Coll Surg 2007; 204: 1178-1187. http://dx.doi.org/10.1016/j. jamcollsurg.2007.03.022

24. Di Leo A, Puffer S, Ricci F, et al. Surgical site infections in an Italian surgical ward: A prospective study. Surg Infect 2009; 10: 533-538. http://dx.doi.org/10.1089/sur.2009.008

25. Narong MN, Thongpiyapoom S, Thaikul N, Jamulitrat S, Kasatpibal N. Surgical site infections in patients undergoing major operations in a university hospital: using standardized infection ratio a benchmarking tool. Am / Infect Control 2003; 31: 274-279. http://dx.doi.org/10.1067/mic.2003.65

26. Geubbels EL, Nagelkerke NJ, Mintjes-DeGroot AJ, Vandenbroucke-Grauls CM, Grobbee DE, de Boer AS. Reduced risk of surgical site infections through surveillance in a network. Int J Qual Health Care 2006; 18: 127-133. http://dx.doi.org/10.1093/intqhc/mzi103

27. Rioux C, Grandbastien B, Astagneau P. Impact of a six-year control programme on surgical site infections in France: results of the INCISO surveillance. / Hosp Infect 2007; 66: 217-223. http://dx.doi.org/10.1016/j.jhin.2007.04.005

28. Wilson AP, Hodgson $B$, Liu $M$, et al. Reduction in wound infection rates by wound surveillance with post discharge follow-up and feedback. Br J Surg 2006; 93: 630-638. http:// dx.doi.org/10.1002/bjs.5303 